\title{
Monumentos y arte urbano: percepciones, actitudes y valores en la ciudad de Manizales
}

\author{
Monuments and urban art: perceptions, attitudes and values in the city of Manizales
}

\section{Rodrigo Santofimio-Ortiz}

Universidad de Caldas, Manizales (Colombia)

Departamento de Antropología y Sociología

Sandra Milena Pérez-Agudelo

Universidad de Caldas, Manizales (Colombia)

Departamento de Antropología y Sociología

\section{Rodrigo Santofimio-Ortiz}

Sociólogo, Universidad de Antioquia. Medellín (Colombia).

Magister en análisis de problemas económicos, político e internacionales contemporáneos, Universidad Externado de Colombia. Bogotá (Colombia).

Profesor titular, Departamento de Antropología y Sociología, Universidad de Caldas. Manizales (Colombia).

(D) https://orcid.org/0000-0002-667I-0887

(a) rodrigo.santofimio@ucaldas.edu.co

Sandra Milena Pérez-Agudelo

Antropóloga, Universidad de Caldas. Manizales (Colombia).

Tesista del Programa de Antropología, Universidad de Caldas. Manizales (Colombia).

(D) https://orcid.org/0000-0002-9030-1776

(1) amilxhora-@hotmail.com

Santofimio-Ortiz, R. y Pérez-Agudelo, S. M. (2020). Monumentos y arte urbano: percepciones, actitudes y valores en el caso de la ciudad de Manizales. Revista de Arquitectura (Bogotá), 22(2), 37-47. https://doi. org/10.14718/RevArq.2020.2221

\section{Introducción}

Vivimos los lugares y ellos nos viven a nosotros; aprendemos a mirarlos y hacerlos nuestros.

Asier Rúa (2016)

La presente reflexión hace parte de la investigación Monumento, arte urbano y espacio público, llevada a cabo durante 2017 y 2018, y cuyo objetivo era comprender el papel de los monumentos y del arte urbano en las ciudades, y su relación con el espacio público, a partir de la hipótesis de que su relacionamiento y su interacción dialéctica no solo permiten una comprensión más holística de la ciudad, sino que también muestran las complejidades, entre ellas el papel de los monumentos y el arte urbano; en el caso del espacio público, la problemática pasa por su apropiación y disfrute en un ámbito urbano capitalista restrictivo y bajo la lógica del "valor". La investigación se realizó a instancias del grupo de investigación Idacanzas, cuya línea de investigación tiene que ver con el tema ciudad y ciudadanía. La investigación fue desarrollada con el soporte financiero y el apoyo de la Universidad de Caldas, como reconocimiento el tiempo y la dedicación del docente, así como de los requerimientos técnicos, del trabajo de campo y bibliográficos.

La lectura de la ciudad, sus representaciones y los imaginarios que de ella hacen los actores sociales, de manera individual o colectiva, se estima que hunde sus raíces en trabajos emblemáticos en esa episteme, como los de Lynch (1966), intitulado The image of the City. Un interés de análisis que décadas más tarde fue retomado y redimensionado en la obra intitulada Topofilia. Un estudio de las percepciones, actitudes y 
valores sobre el entorno, de Fu Tuan (2007), con el fin de aprehender la forma y el contenido en esas relaciones que los ciudadanos (actores, en nuestro caso) presentan para con la ciudad y la forma como esta es percibida, apropiada y expresada de acuerdo con lugares, sitios, clases sociales, ambientes y actividades. Dichos actores diseccionan las ciudades creando toponimias, así como representaciones a manera de signos o códigos (emblemas), que condensan su trama, o bien, retrayéndola, aunque de forma sintética, en un epígrafe o en un emblema, con los cuales pretenden definirla: "Medellín, ciudad de las flores", "Pereira, querendona, trasnochadora y morena", "Manizales, la ciudad de las puertas abiertas"...

¿Puede la ciudad ser contenida solo a través de emblemas o epígrafes? Esto es, ¿a través de códigos o símbolos? ¿Es suficiente el recurso heurístico —en este caso, la hermenéutica urbana o la semiótica - para develar la complejidad de la ciudad contemporánea? Es la posición de este documento que, en efecto, es así, y en tal sentido, se propone, para el siguiente ejercicio, la lectura de la ciudad: su interpretación a través de los monumentos históricos y del arte público, que se denominarán, en lo sucesivo, arte urbano. En ese caso, entonces, vale la inquietud: ipueden los monumentos históricos — en este caso, la estatuaria alegórica o figurativa, así como el arte urbano- propiciar elementos interpretativos y comprensivos acerca de la ciudad?

Ahora bien, si la respuesta a lo anterior es afirmativa, ¿qué develan y qué traducen los actores, los espectadores o los viandantes, quienes viven y "palpitan" la ciudad, acerca de su relación con los monumentos y el arte urbano?

Así mismo, ża qué tipo de interpretación, en términos de actitudes y valores, aluden los actores respecto a los monumentos y el arte urbano? ¿Acaso esas actitudes y esos valores podrían darnos pistas acerca de la relación de los actores con la ciudad, cuyas vivencias experimentan cotidianamente? ¿Es posible, a través de esas percepciones, esas actitudes y esos valores, construir narrativas sobre la ciudad?

\section{Del soporte analítico y conceptual}

La presente investigación, en primer lugar, deriva su soporte analítico y conceptual de la postura de Borja (2002), en tanto que esta concibe, para el presente documento, el espacio público como más que calles o edificios; esto es, no solo desde su comprensión racional y jurídica únicamente. Para la formulación del presente estudio, se parte de presuponer que los espacios públicos son esos lugares donde los ciudadanos llevan a cabo sus vivencias cotidianas, políticas y sociales; la planificación en tal sentido, como afirma Borja (2000), suele obviar ese elemento, al insistir en la reglamentación y el orden; así, entonces, la historia de la ciudad es la de sus espacios públicos, pues los ciudadanos, hombres y mujeres que hacen la ciudad, se muestran y ejercen su condición de ciudadanos allí, de cara a los monumentos y al arte público, los cuales, a manera de toponimias, no solo refieren a una forma que la evidencia y a un contenido, como experiencia de vida, plasmada en esos ciudadanos que las observan, las interpretan o, incluso, interactúan con ellas o reconstruyen su historia, para el caso de los monumentos, y reinterpretan las narrativas del arte, de su entorno y de la vida misma de quienes participan en su composición.

La relación entre los ciudadanos y la ciudad se concreta a través de los monumentos y el arte urbano, en el ámbito de calles, plazas y parques, como lugares de encuentro y espacios de uso colectivo, debido a la apropiación progresiva de estos reconstruyendo así, además del pasado, un orden y, más que un orden, un sentido, traducido a través de toponimias: las que son retraídas de manera espontánea, directa, inmediata, lo que, sin duda, más allá del ámbito físico, traduce una expresión colectiva, la diversidad social y cultural de la que está imbuida. Esto es, parafraseando a Borja et al. (2003), la trama en la ciudad para los ciudadanos, quienes la viven como un hecho "natural", aun en situaciones críticas, frente al riesgo, pues la constituyen de forma subjetiva, de acuerdo con el vivir cotidiano. En síntesis, y citando nuevamente a Borja et al. (2003):

\footnotetext{
Las tramas urbanas son las formas particulares como se configuran los espacios a partir de grandes sucesos, mitos, historias de vida, conflictos y las experiencias significativas de los agentes sociales, dependiendo del lugar, por lo tanto, las tramas sólo son posibles evidenciar a través de la comprensión de la cotidianidad y las prácticas que se desarrollan al interior de esos lugares. (Citado por Sáenz, 2017, p. 37)
}

Otro soporte analítico que refiere la presente investigación tiene que ver con el tema de las representaciones sociales: en efecto, si se considera la perspectiva de Moscovici (1985), citado por Sáenz (2017, p. 26), partiendo de la interacción no solo con los espacios públicos (calles, parques o plazas), sino también, con los monumentos y el arte urbano, los actores construyen formas particulares de representar y presentarse el espacio público a la manera de un "sentido común". Esa interacción, a través de la comunicación por medio de gestos, al decir de Sáenz (2017), origina productos culturales con existencia concreta: el lenguaje proporciona un medio para la operación de la actividad cognoscitiva superior; los mitos, surgidos de esa base, dan forma a la capacidad humana para imaginar, y las costumbres enmarcan las referencias dentro 
de las cuales operan las opciones individuales y la voluntad. Así pues, tanto las calles como los parques - y junto a ellos podrían proponerse los monumentos y el arte urbano- son lugares propicios para el rastreo de las formas particulares de cómo los ciudadanos se comunican e interactúan; esto es, y retrayendo nuevamente a Sáenz $(2017$, p. 27), "se puede afirmar que dependiendo de los contextos, interacciones y circunstancias, los actores en los espacios públicos se comunican y se expresan de manera diferente".

\section{Metodología}

El universo poblacional referido a la investigación considera una porción aleatoria de los habitantes de la ciudad (hombres y mujeres, adultos y jóvenes), su relación cercana o distante con los monumentos y el arte público, y la cercanía respecto a los objetos de investigación; alude, además, a una interacción fluida y dinámica en tanto se vive cerca de dichos objetos o se transita cotidianamente con ellos. Por otro lado, también fue importante indagar y percibir la apropiación de los actores respecto a los objetos urbanos, su percepción relativa. No obstante la distancia que los separa de ellos, aquellos los abstraen como posibilidad de aprender la ciudad, como lugares toponímicos; es decir, partiendo del monumento mismo y de su sensación a sus vidas, y también, como lugares emblemáticos de la ciudad. Así, entonces, la ciudad, a través de los monumentos y el arte público, funciona no solo en tanto dispositivos con los cuales ella puede ser representada o imaginada, sino que también los monumentos expresan, como lo sugiere Fu Tuan (2007), las posibilidades de topofilias o de sensaciones y de emociones, o bien el rechazo, el miedo o el recuerdo simpático, agradable, en correspondencia con sensaciones agradables, de confianza y seguridad, de forma que la vida se disponga para su disfrute.

La muestra se conformó a partir de hombres y mujeres, 30 en total, y se hicieron entrevistas semiestructuradas, referidas en primer lugar a su identidad personal y social, su ocupación, su lugar de residencia y su relación con el lugar, entre otras inquietudes, y seguidamente, la interpretación que se hacía de los objetos y el sentido que se les daba: monumentos y arte urbano, en términos del significado que apropiaban para sí; ello, sin discutir, por parte de los investigadores, sus interpretaciones, porque, en síntesis, de lo que se trataba era de llegar a una construcción significante desde los actores, en consideración de cómo leían el monumento o el arte urbano y también de cómo lo incorporaban a sus mapas, a la manera de guía, para vivir, imaginar y aprehender la ciudad; y para efectos de hacer redun- dante y cumplir el ejercicio en la comprensión de las representaciones sociales, que hacen los actores, sus actitudes y sus valores se recurre al método etnográfico, para observar el discurrir cotidiano de los actores en los entornos y en sus relaciones con los monumentos y el arte urbano. Cabe observar que la aplicación de dicho método en la presente investigación posibilitaba ajustar o cualificar esas representaciones sociales con el fin de darles un encuadre más enriquecedor a las interpretaciones. Finalmente, se propone como recurso metodológico el uso de una entrevista, hecha al artista, escultor y profesor Alberto Reyes, denominado en el presente documento como Informante 1.

\section{Monumento y ciudad}

¿Acaso los actores se preguntan acerca del papel de los monumentos históricos en la ciudad - esto es, de aquellas figuras hechas, entre otros materiales, de piedra, cemento, hierro o madera-, y que regularmente se encuentran bien sea en avenidas, parques, centros comerciales, glorietas o, sencillamente, en las rutas habituales de tránsito peatonal?

Yory dice que su presencia en la ciudad no es casual o desprovista de intención: al contrario, "[...] el monumento resulta ser no otra cosa que una manera de nombrar, al establecer una determinada relación con aquello que consideramos que debe permanecer $y$, por lo mismo, merece ser editada [...]" (2002, p. 9).

El carácter histórico que presentan los monumentos, en tanto "su anhelo de eternidad, de apresentificación perpetua, tendría que ver con la insistencia y el deseo personal por retraer ese pasado o esa historia [...]; en esa forma de monumentalizar nos monumentalizamos, nosotros mismos" (Yory, 2002, p. 9).

Ahora bien, el monumento, más allá de su carácter referencial e histórico, tiene que ver también con su "valor parlante"; esto es, "su manera de comportarse como palabra, signo o, en cualquier caso, lenguaje" (Yory, 2002, p. 10). En este caso, la paradoja del monumento, en tanto expresión simbólica, es que tiende a agotarse en su propia significación, pero, así mismo, puede el monumento a manera de "remedio" —expresión de Yory (2002)—, permitir a los individuos ubicarse en la ciudad.

La ciudad del ahora, claro está, propondría a priori la dificultad de que se establezcan ese tipo de relaciones o aspiraciones con sus monumentos $y$, en concordancia con lo anterior, nadie esperaría que una escultura o un busto, cualquiera sea el material o la imagen que traduce, produzca sensaciones más allá de la simple referencia visual; en parte, por los procesos de globalización y, en parte, por la lógica en que 
se ordenan las ciudades, o bien, por la primacía de lo que Lefebvre (1969) denominaba el "valor de cambio" en el que se constituyen las ciudades a expensas del "valor de uso", de acuerdo con esa lógica, en cuya primacía se establecen las ciudades, y que privilegia a la planificación urbana como instrumento de sumisión a la ciudad frente a las demandas del capitalismo; y contrario al "espacio urbano" como locus ludus, en el que la ciudad es preservada y recreada. De esta manera, los parques, por ejemplo, no funcionan como "pulmones", sino que se integran al espacio ciudadano como elemento de encuentro de las calles y las avenidas, planeados para la hipermovilidad, en consecuencia (Sassen, 1999). Ciertamente, Viviescas reconoce que la ciudad capitalista, aun constituida sobre la ley del valor, también plantea otras tendencias en su interior, que coexisten y se manifiestan, y que "generan una dinámica muy fuerte de renovación constante" (1989, p. 40).

¿Cuál sería, entonces, el destino de los monumentos que caracterizan a la ciudad?

Yory (2002) parece centrar este destino entre la homogeneidad, propia del "nuevo orden global", con sus valores, sus significados y sus lenguajes, el multiculturalismo, como diría Sassen (1999), y la indiferenciación espacial, que tiende a uniformar los diferentes contextos. Pero, así mismo, o correlativo a ello, emerge el "aullido de los particularismos"; esto es, el estridente grito de lo local, que clama por un espacio y por defender su pequeño reducto, como alude Yory (2002, p. 47); en síntesis, al espíritu de los tiempos se sustraen los monumentos, los cuales ya no parecen gravitar en ese instante de posteridad. Así, entonces, vale preguntarse, como plantea Yory (2002): ¿Qué se monumentaliza hoy?

\section{Resultados}

\section{Los monumentos y las representaciones sociales}

La ciudad de Manizales actualmente cuenta con más de 380.000 habitantes, y conurbada con el municipio de Villamaría supera los 400.0001; es la segunda ciudad en número de habitantes, después de Pereira, en lo que actualmente se denomina la ecorregión Eje Cafetero, y que con la ciudad de Armenia constituyó en su momento una sola unidad político-administrativa denominada Departamento de Caldas, en 1905 (Valencia et al., 2006).

La ciudad está administrativamente constituida a partir de comunas, así: la comuna Atardeceres, cuyos estratos preferentes son 2, 3 y 4; Ciudadela del Norte, con estratos preferentes 1 , 2 y 3; Cumanday, con estratos preferentes 3 y 4; Comuna Cerro de Oro, con estratos preferentes 2, 3 y 4; Estación, con estratos preferentes 3, 4, 5 y 6; La Fuente, con estratos preferentes 1, 2, 3 y 4; La Macarena, con estratos preferentes 1, 2 y 3; Palogrande, con estratos preferentes 4, 5 y 6; San José, con estratos preferentes 1,2 y 3 ; Tesorito, con estratos preferentes 3, 4 y 6 , y Universitaria, con estratos preferentes 1,2 y $3^{2}$.

El referente en términos de estratificación para la ciudad, no es casual, en tanto la variable permite, para efectos de la presente investigación,

1 Población ajustada municipal, Censo 2005, DANE.

2 División Territorial Comunas, Alcaldía de Manizales, Secretaría de Planeación, abril de 2015; advertir que la preferencia de estratos por comunas se hizo a partir de un análisis de frecuencias, lo que necesariamente plantea rangos para todos y cada uno de los estratos.

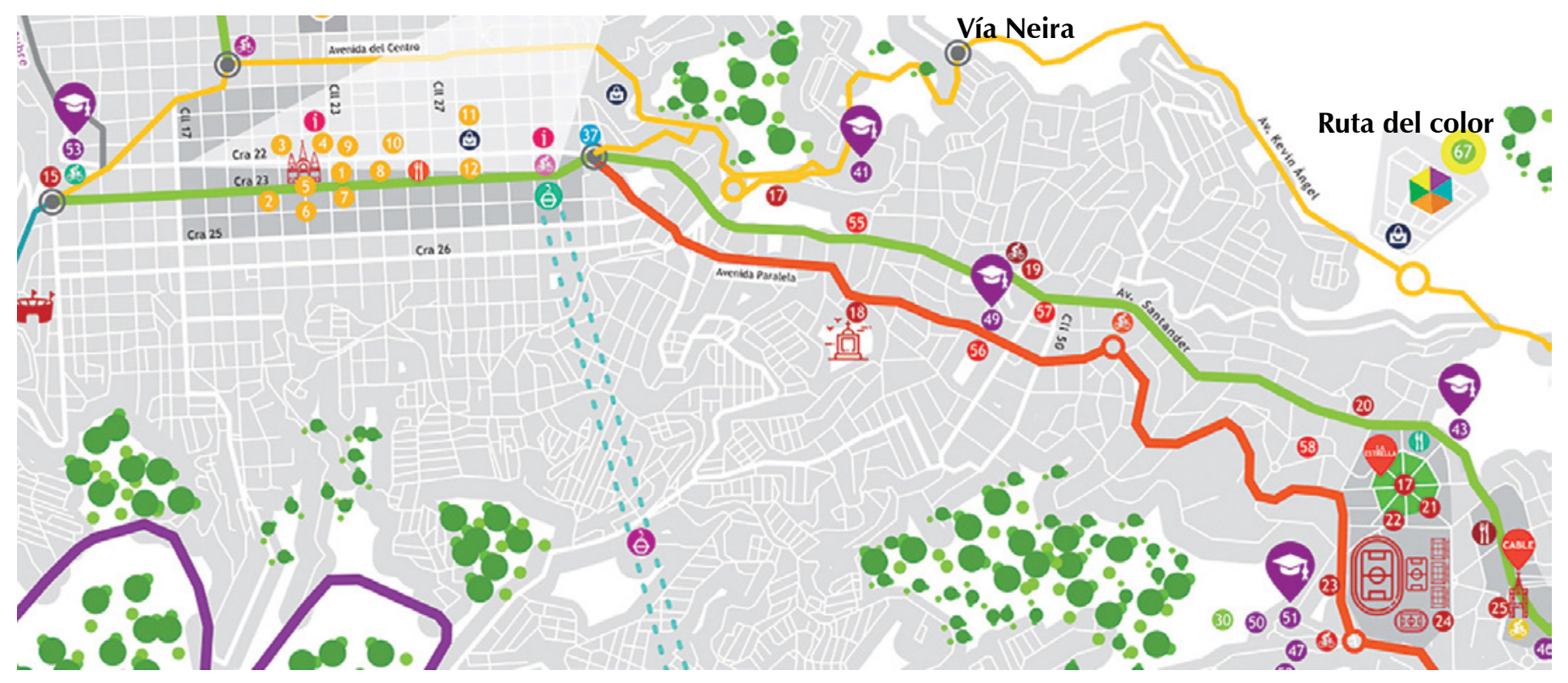

(A) Figura 1. Aspecto de la localización de los tres ejes viales importantes de Manizales.

Fuente: Alcaldía de Manizales (2018).

Recuperado de: http://manizales.gov.co/RecursosAlcaldia/201811272305111789.pdf CC BY 
relacionar la presencia o la ausencia de los monumentos, y es evidente, en ese caso, que los monumentos más emblemáticos de la ciudad se ubican o tienen mayor presencia en las comunas que discurren en una estratificación asociada a los estratos socioeconómicos 4, 5 y 6; es decir, aquellos con mayor poder adquisitivo. Ahora bien, la estratificación social por comunas tampoco niega la presencia de monumentos en los estratos 1, 2 y 3 , distinguidos, en comparación con los anteriores, por su menor poder adquisitivo, y donde, regularmente, son ubicados estos monumentos en las troncales o las avenidas que discurren periféricamente por esas comunas, lo cual los hace, en muchos casos, casi inexistentes en el imaginario de su habitantes, o si los aluden no reconocen de qué o de quién se trata, qué representan o dónde espacialmente se encuentran ubicados con exactitud.

La ciudad, así mismo, en términos de un ensamble de movilidad, discurre a través de tres ejes viales importantes. Uno de ellos tuvo su origen durante la década de 1920, y fue denominado inicialmente como Avenida Cervantes, y posteriormente, ya en el decenio de 1950, como Avenida Santander, y que recorre la ciudad de occidente a oriente. El otro eje vial se denomina Avenida Paralela. El tercer eje vial, de constitución más reciente, es la Avenida Kevin Ángel, o Avenida del Río, que discurre del Norte hacia el Oriente de la ciudad.

Las características topográficas de la ciudad, que es cordillerana, además de las bondades del clima frío más que templado, ubican la centralidad alrededor de un eje vial: la Avenida Santander, enclavada y desplegada a través de una cresta, o cuchilla, y correlativamente en sus inclinaciones, las dos avenidas ya mencionadas, casi discurriendo en paralelo, también en sentido occidente-oriente ${ }^{3}$. A través de las tres avenidas representadas en la figura 1 , discurre no solo la dinámica de movilidad de la ciudad, sino que en ellas también hacen presencia los monumentos de héroes, de personajes importantes en la historia de la ciudad, ya sea políticos o literatos; también, monumentos conmemorativos o alegóricos a las particularidades de la ciudad, así como a otras conmemoraciones, bien sea de eventos deportivos, efemérides, de carácter eclesiástico o de expresión artística. Así mismo, los monumentos referidos a la historia o a lo conmemo-

3 Esta traza urbana hunde raíces a partir de los años cincuenta del siglo XX, con base en disposiciones de orden nacional, $y$ también, a partir de las discusiones generadas y ambientadas desde la revista Civismo, de la Sociedad de Mejoras Públicas, al tenor del "Plano Regulador", cuya premisa sería que: "[... permita a Manizales su desarrollo urbano en armonía con los imperativos de su topografía [...] aprovechando exitosamente la estructura caprichosa de su suelo", Carlos Arturo Jaramillo, alcalde de la ciudad, "El centenario. Plano Regulador", en Civismo N. ${ }^{\circ}$ 97, agosto de 1952, S. M. P., p. 18
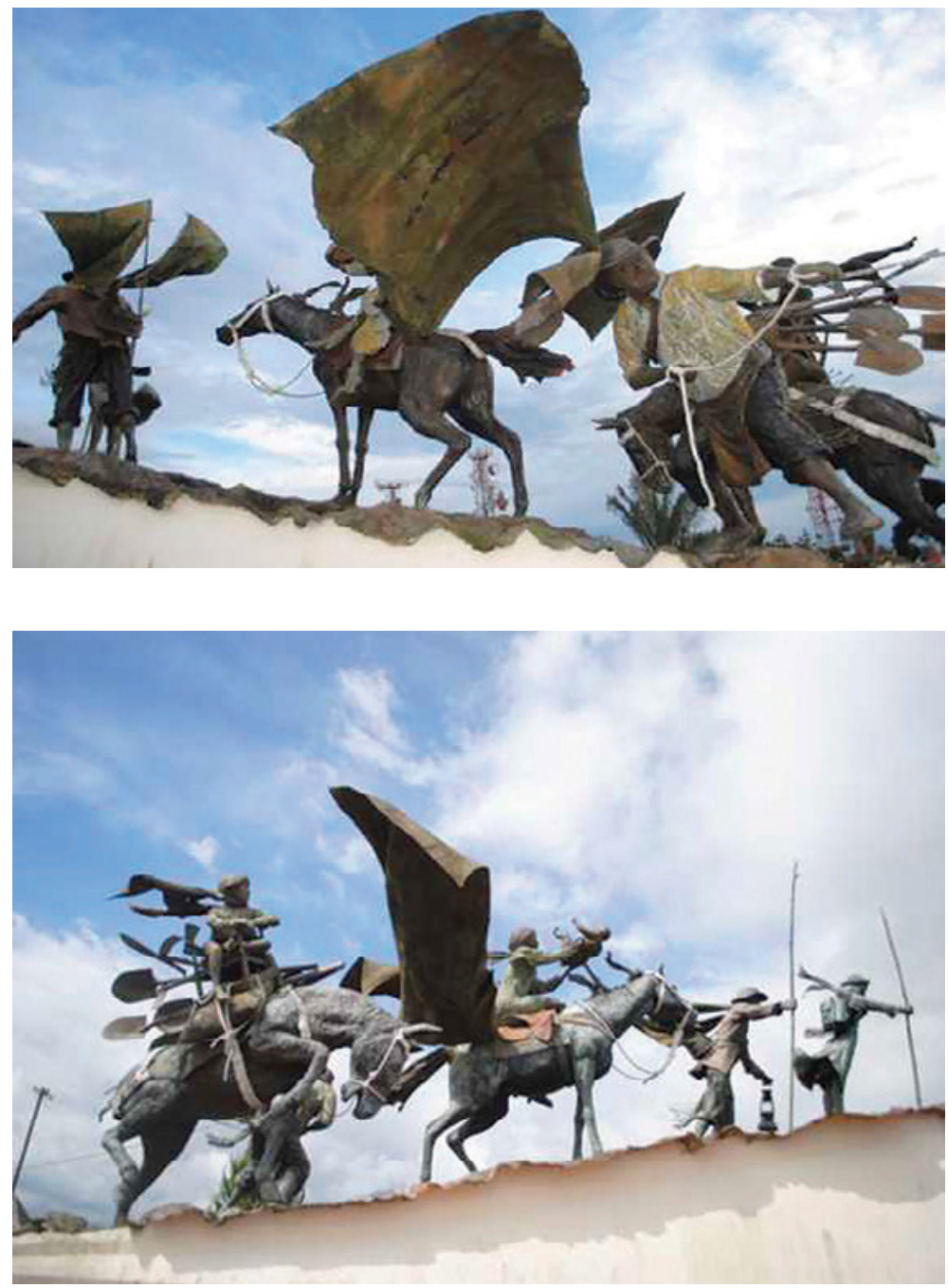

rativo se traslapan con aquellas esculturas, o arte público, que traducen un simbolismo estrictamente artístico; empero, el transeúnte que los observa y los disfruta no hace esas distinciones, a no ser que sus propósitos sean diferentes de los del simple observador.

El plegable que difunde el Instituto de Cultura y Turismo (Instituto de Cultura y Turismo, 2005) anuncia como "patrimonio escultural" de bienes muebles un total de 26 monumentos, distribuidos a lo largo y ancho de la ciudad, y los cuales no necesariamente corresponden al fluir y el confluir de la dinámica demográfica y de movilidad de los habitantes en la ciudad; esto es, de su centralidad, como lugares toponímicos o de encuentro. También varios de esos monumentos traslapan su representación como arte público, y no propiamente ajustados a la definición a la que ya aludimos para los monumentos. Sobre el arte público y su incidencia en el entorno urbano se formularán observaciones en otro apartado de este Informe.

Ahora bien, sobre el papel del monumento en la centralidad de la ciudad puede dar cuenta el Monumento a los colonizadores, obra de Luis Guillermo Vallejo (1997-2002), ubicado en la Avenida 12 de Octubre, o bulevar de Chipre, y a la cual se llega accediendo a un pequeño parque
Monumento a los colonizadores: "La Agonía". Fuente: elaboración propia (2018). CC-BY-NC 4.0 


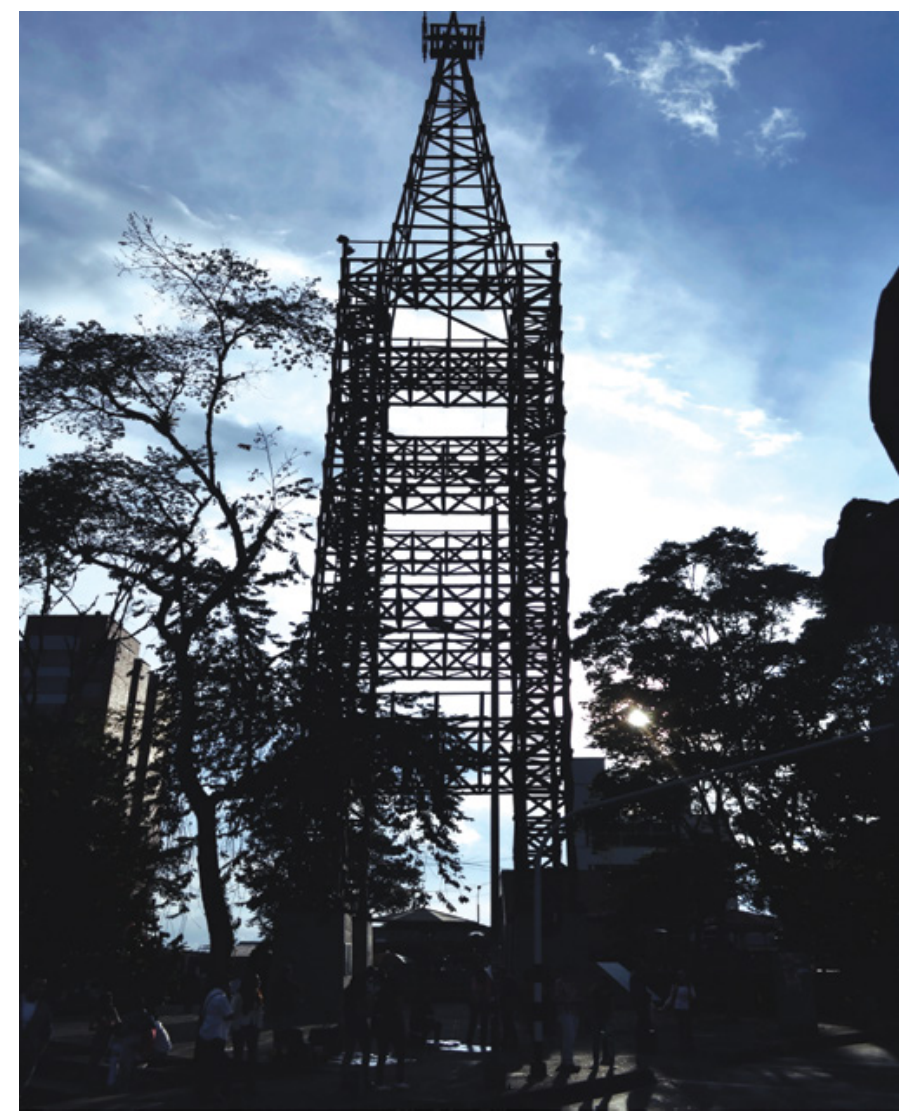

(A) Figura 4. La torre del cable.

Fuente: recuperado de: EnBrazosDeLaFiebre. http:// commons.wikimedia.org/ wiki File: Torre del Cable, Manizales, Caldas, Colombia. JPG (2013) CC-BY-SA 4.0 (el antiguo jardín botánico), según dice el escultor y profesor Alberto Reyes (2016):

[...] es una escultura inacabada... en bronce fundido, que consta de varios elementos figurativos, la cual se puede observar desde varios ángulos, gracias al emplazamiento en que se encuentra, este trabajo, aunque es de reciente manufactura está inacabado, y se aprecia claramente los diversos faltantes en las piezas constitutivas de las obras, así como falta de acabados en la cimentación y la estructura de apoyo, la escultura relata ocho niveles circulares tejidos por los caminos de herradura, camino del norte, camino de la Moravia, camino del Ruiz y del Cauca, evocando las historias de herrería; la obra con un peso total de 25 toneladas, y las escenas están conformadas por un colonizador, dos arrieros, una mujer, un bebé, dos niños, dos perros, un caballo, cuatro bueyes, y cuatro mulas, con baúles, materos y un menaje completo de viaje [...]. (Informante $n^{\circ} 1$ )

De acuerdo con el autor de la escultura, en la obra, simbólicamente, se logra distinguir dos etapas: "La Agonía" y "El Éxtasis". La primera etapa, en la parte inferior de la escultura, traduce la proeza de los fundadores que llegaron desde el sur de Antioquia (Abejorral, Sonsón, Rionegro, La Ceja y Marinilla), y reivindica la vida familiar, como se aprecia en la figura 2.

La otra etapa, "El Éxtasis", que se halla en la parte superior del trazo escultural, representa el triunfo en la epopeya, el cual expresan las personas y los animales, de cara al paisaje, en la felicidad de sus rostros. La fuerza simbólica y la narrativa en la escultura nos muestran la gesta colonizadora a través del esfuerzo, el sacrificio y el arrojo, y no menos, los avatares; entre ellos, el ligado a las dificultades y las particularidades de un territorio con una topografía agreste e indómita, cuya conquista culmina con la fundación de la ciudad de Manizales (1849), simbolizada en la figura de la catedral. Algo de todo esto es observable en la figura 3.

El monumento traduce la síntesis más elaborada del carácter antioqueño en esta parte del país, como esencia histórica y fundacional de la ciudad; empero, el monumento no ofrece la mejor ubicación a la hora de evaluar su impacto en la percepción que de su mensaje hacen los actores $^{4}$, pues solo se le retrae durante los eventos feriales de la ciudad, o bien, en visitas programadas; más allá de ese contexto, da la impresión de que el monumento cae en el olvido, pues difícilmente se alude a él en las entrevistas con aquellas personas ubicadas en otros lugares de la ciudad. Por otro lado, la interpretación que se hace del monumento, si bien tiene que ver con la familia, con la vida en el campo y, por qué no, con la gesta colonizadora, tal como en ciertas respuestas se alude; pero difícilmente los entrevistados relacionan su experiencia cotidiana con el monumento y parte vivencial en la ciudad. En síntesis, retomando a Lynch (1966), para el caso del Monumento a los colonizadores, este no podría denominarse, precisamente, como una "imagen ambiental eficaz", en tanto no es proveedor de una "fuerte sensación de seguridad emotiva" (p. 18); empero, como el entorno en el que se ubica el monumento se ha constituido en "zona rosa", o ruta habitual de fiesta de la ciudad, las personas entrevistadas - jóvenes, mayoritariamente- dejan ver sus percepciones del monumento aclarando que no están allí por el significado que traduce este, su "fuerza simbólica", sino porque el sitio permite "pasarla bien" y "gozar la vida", y si ambas situaciones son coincidentes o correlativas, esas son circunstancias emergentes o azarosas.

El otro monumento, de tanta importancia como el ya referenciado, tiene que ver con La torre de Herveo, o Torre del cable; aunque, obviamente, este último monumento se acerca idealmente al concepto de centralidad que deberá concitar la relación entre monumento y los actores en la ciudad.

La ubicación del monumento tiene que ver correlativamente con el desarrollo urbanístico de la ciudad, siguiente la traza hacia el Oriente, con edificaciones, viviendas para los sectores de clase social media y locales comerciales, y allí, en esa traza, discurre la Avenida Santander; así, el punto de inflexión de esta nueva lógica urbanística se dio también con la declaratoria de "zona rosa", a un recorrido a través de dicha avenida en más de diez o doce cuadras, donde hay centros comerciales, universidades, hipermercados,

4 "La ubicación en donde está la obra no es la mejor, pues ese lugar es un mirador, un mirador natural y paisajístico que tiene la ciudad"; apreciación del escultor y profesor Alberto Reyes, entrevista 2 de mayo de 2016. 
bares, sitios de comidas, consultorios y oficinas de comunicaciones, con zonas recreativas, y en cuya afluencia y confluencia sociológicas puede observarse la presencia mayoritaria de gente joven. Esto coadyuva a visibilizar el fenómeno de juvenilización de los referidos espacios, además de la centralidad que ocupa el monumento La torre del cable, como sus características relevantes, según muestra la figura 4.

El monumento debe su nombre a una torre de madera, con fecha de inicio en el sitio desde 1983, con $54 \mathrm{~m}$ de altura, réplica de aquellas torres de metal que se construyeron como pilotes o soportes (más de 376), para el cable aéreo que desde abril de 1922 unía a Manizales con Mariquita, en un trazado de $70 \mathrm{~km}$; el cable aéreo se empleaba para el transporte de mercancías; preferentemente, el envío de sacos o cargas de café al exterior. El entorno cercano al monumento constituyó para la década de 1920 una zona de descargue de mercancías o estación; también, el patio de bueyes. Hoy quedan ahí la sede de la Facultad de Arquitectura de la Universidad Nacional de Colombia, sede Manizales, en una casa de la época republicana en la ciudad (1920), y el parque Antonio Nariño; además, la zona es un lugar de encuentro de jóvenes, con una alta concurrencia, adecuado como local o tienda para la venta de bebidas derivadas del café.

El monumento, en sí, no traduce una significación más allá del encuadre geométrico que lo envuelve, la altura que alcanza y la visibilidad que concita en un radio de varias cuadras a la redonda; por ello, visitantes o actores tienen que ver con el monumento solo en tanto les permite una ubicación y una determinación espacial concretas y de orientación en la ciudad, y así, entonces, podría decirse que La torre del cable se encuadra idealmente en lo que sugiere Lynch como "imagen ambiental", pues

\section{[...] presenta una identidad en tanto como monumento al Cable se le identifica indiscuti- blemente con respecto a otros monumentos en la ciudad, además de presentar una relación espacial o pautal con otros objetos del entorno $y$, finalmente, expresa: 'un cierto significado prác- tico o emotivo al observador'. (1966, p. 18)}

Las entrevistas dejan traducir la percepción relativa del monumento en los jóvenes, por supuesto, así como una relativa apropiación acerca de su origen, cuando se logra establecer relaciones coherentes entre el monumento y la historia de la ciudad, ligada al cable aéreo de 1922. Los jóvenes, así mismo, y los adultos en general, lo conciben como algo importante en la centralidad en la ciudad, y cualquier intento de reubicación o traslado lo verían como atentatorio, no solo contra la gente y visitantes, sino también, en menoscabo de su importancia estética y, lo más importante, su clara referencia alegórica a la ciudad y a su historia.

¿Qué prescripciones o valoraciones suscita el monumento en los actores? Ninguna, de acuerdo con las respuestas que dieron las personas participantes; tan solo la referencia espacial que suscita el nombre de La torre del cable, o "el cable", como lugar de encuentro o para su ubicación en algún espacio concreto de la ciudad, bien que haya interés para "compartir con amigos", o bien que permita la referenciación espacial para ir al encuentro o la realización de alguna actividad en su entorno, es en lo que parecen coincidir las entrevistas, aunque se requiera a actores que tienen como origen lugares distantes y apartados del monumento, como, por ejemplo, barrios perimetrales de la ciudad o la Plaza de Bolívar. Así, La torre del cable como monumento traduce, empleando la terminología de Lynch (1966), "imaginabilidad"; esto es, una imagen indiscutible para los entrevistados es también una "imagen ambiental", legible rápidamente y visible o "vívidamente identificable" y de utilidad, pues permite que los ciudadanos o los actores se orienten en su relación con el medio ambiente urbano de la ciudad.

\section{Arte urbano y ciudad}

¿Por qué y para qué el arte urbano en la ciudad? Esta inquietud hunde raíces primariamente en aquel momento de los años sesenta del siglo $\mathrm{XX}$, cuando el arte y sus protagonistas —es decir, los artistas, sus creadores- decidieron que el arte no se contenía únicamente en el ámbito de un museo o de una galería: debía ir más allá de esos espacios cerrados, exclusivos y para un público especializado. Así pues, los artistas en esa ocasión manifestaron lo necesario de que la ciudad "fuera el gran museo urbano", tan grande como ella misma, y allí, sin exclusiones o distinciones, apreciar y degustar la obra de arte, así como hacerla parte integral de la misma ciudad.

Entonces, fue claro para los artistas que "[...] sin el 'libre acceso' de los ciudadanos, el arte público entra en contradicción consigo mismo", de acuerdo a Baudino (2008), citado en Maderuelo (1994).

El otro elemento de análisis, dice Baudino (2008), tiene que ver con los límites establecidos por el arte público y los monumentos: el primero le confiere al contexto "una idea de horizontalidad, de igualdad y de diálogo entre la obra y el espectador" (p. 5), lo cual supone pensar en el contexto en que se ubica la obra de arte, con dos intenciones: comunicación y funcionalidad.

Ahora bien, Cruz-Arrillaga, por su parte, sostiene que, además del arte en su mediación artística, también debe tener como función "la formación de las personas", esto es, un arte público como 
"espacio educativo" (2014, p. 145), en tanto participan de él, tres agentes: "los promotores quienes valoran y legitiman los proyectos de arte público, los artistas, quienes crean la obra de arte y significan los espacios públicos y, finalmente, los ciudadanos quienes recrean dichos significados" (p. 148).

No obstante lo anterior, existe la crítica respecto de cuál es en verdad la participación de los ciudadanos, no solo en la percepción, la interpretación y la generación de diversos significados de la obra de arte, así como también en las propuestas que han de constituirse para su "puesta en escena", pues, de acuerdo con Cruz-Arrillaga (2014), estas se conciben como "propuestas modeladas", producto de ambientes "normatizados e institucionalizados, sin apenas la participación ciudadana" (p. 153).

Para el escultor y profesor Reyes (2016) (Informante $\mathrm{N}^{\circ}{ }^{0} 1$ ), al analizar la obra artística en el entorno urbano —espacio público-, bien sea escultura, grafiti, mural o pintura, se hace necesario revisar también el entorno en el cual "va habitar la obra artística... [su] razón de estar allí". Así pues, no se habla únicamente de la obra artística en sí misma, sino también, del vínculo que aquella establece con el espacio público, pues de lo que se trata como principio de la obra es de su capacidad para "dialogar e interactuar y participar" con el actor, el peatón o el espectador, dice Informante N. ${ }^{\circ} 1$ (2016), pues "las obras y su entorno - háblese de espacio público o privado- - pueden llegar a estar "aisladas, desactualizadas o descontextualizadas", o, incluso, al margen de la circulación en la trama urbana, en ese caso, entonces, riñen con el entorno, pues de lo que se trata es de que la obra artística participe e intervenga en el espacio público, bien sea en un sentido patrimonial, estético o socialmente; "en perspectiva —dice Maderuelo (1994), citado por Reyes (2016) [Informante N. ${ }^{\circ}$ 1] -, al desarrollo de la ciudad": en su transitabilidad, sus recorridos, su luz, su paisaje y sus peatones.

Por otra parte, la escultura, como

[...] arte público debe ayudar a restituir al hombre su carácter de peatón, de ser humano, capaz de reconocer su sensibilidad, su carácter de ciudadano [...] es una obra, entonces, que llama la atención, que sorprende, que nos saca de la cotidianidad, nos causa asombro, nos muestra algo que no es normal en el transcurrir de la ciudad. (Informante N. ${ }^{\circ} 1$ )

Es así como el arte público devino en arte urbano, al constituirse en parte de la "trama urbana" (Reyes, 2016) (Informante N.o 1), al mejorar patrimonial, estética y socialmente el entorno, al constituirse en parte del amueblamiento urbano y del entramado organizacional, cultural y social de la ciudad; esa simbiosis entre el arte urbano y el espacio público emerge hoy como posibilidad de reivindicar la urbanidad, o el respeto a los de-más, pero también el "derecho a la ciudad", su carácter democrático, de cara a un "urbanismo agresivo" (Zabalbeascoa, 2018), en un capitalismo global, con una lógica financiera e inmobiliaria a través de la gentrificación, cuyo botín, dice: "son las ciudades como rentabilidad, el espacio público vigilado y restringido a la diversidad social y cultural" Zabalbeascoa (2018).

\section{El arte urbano y las representaciones sociales}

¿Qué simbolismos expresa el arte urbano en la ciudad? Pero, también, más allá del arte urbano en sí mismo iqué sensaciones o percepciones devela el arte urbano en los ciudadanos? ¿Traduce sensaciones estéticas el arte urbano en los actores?

En la ciudad de Manizales, el mapa turístico, de autoría de la alcaldía municipal (2018), registra más de una docena de obras distribuidas en el espacio público que bien podrían denominarse —al menos, algunas de ellas_ - "obras artísticas": por ejemplo, el Bolívar Cóndor —ubicada en la Plaza de Bolívar-, realizada por el escultor Rodrigo Arenas Betancourt, y cuyo simbolismo traduce la Libertad, en la forma de un cóndor: "por ser el ave suprema de los Andes"; pero, así mismo, Bolívar como figura heroica, luchó y alcanzó para el continente americano su libertad.

Reyes (2016), es decir, el Informante N.o 1, señala que en el caso del monumento o "artefacto conmemorativo",

\footnotetext{
[Estas obras] aluden a una remembranza, a la nostalgia, con el fin de mantener viva la historia, o memoria colectiva, bien de una gesta heroica o acontecimiento: la Torre del Cable, La locomotora (La Zapata 1), El Arco de la Vida, pero para el avance social y cultural no nos está aportando mucho, pues lo que se encuentra en los libros de historia, lo podrían decir mejor. (Informante N. ${ }^{0}$ 1)
}

El arte urbano, por su parte, tiene una función estética, social y patrimonial, dice Reyes (2016) (Informante N. ${ }^{\circ} 1$ ), aunada ella misma al entorno, porque logra establecer un diálogo con el ciudadano, y este, a su vez, "juega con la obra", "conversa con la obra" (Informante N. ${ }^{\circ} 1$ ):

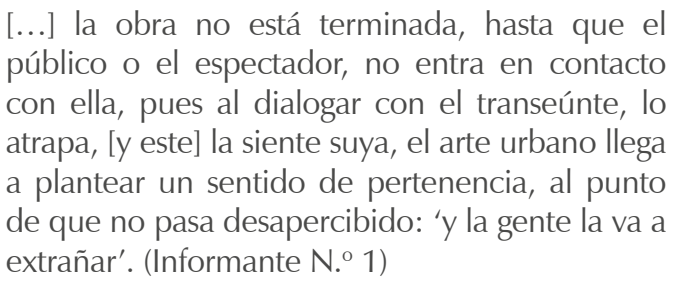

[...] la obra no está terminada, hasta que el público o el espectador, no entra en contacto con ella, pues al dialogar con el transeúnte, lo atrapa, [y este] la siente suya, el arte urbano llega a plantear un sentido de pertenencia, al punto de que no pasa desapercibido: ' $y$ la gente la va a extrañar'. (Informante N. ${ }^{\circ} 1$ )

Se infiere, entonces, que con esa incorporación o puesta en escena del arte urbano, el artista gana para la ciudad y para los ciudadanos un 
"pedazo" de espacio público, el cual se sustrae a la lógica de la privatización en los afanes de la globalización; así, entonces, lo interesante del análisis del arte urbano en el ámbito de la ciudad, como lo sugiere Informante N.o 1, tiene que ver con la reivindicación y la apropiación del espacio público a través de la obra que allí se instala o es puesta por el artista, al conjugar a manera de síntesis, al mejorar, "el lugar en todo sentido" ["de buena recordación"] y, por ende, de interacción cotidiana alcanzando un sentido de pertenencia.

Para estos efectos, se analiza la puesta en escena de dos obras como arte urbano ubicadas en el espacio público de la ciudad: una de ellas es el monumento Bolívar Cóndor (1991), de Arenas Betancourt, ubicado en la Plaza de Bolívar, y que aparece en la figura 5. Sin duda, es una obra de arte para connotar elementos conmemorativos en el imaginario colectivo, y donde, a través de la figura del "hombre-ave" —en este caso, el cóndor-, el artista resalta o exalta la figura del libertador Simón Bolívar; empero, el hecho mismo de encontrarse en un lugar céntrico de la ciudad, como espacio fundacional, comercial y administrativo, genera como efecto que la escultura no resulte atractiva, que no llame la atención o que no concite el interés de los actores para participar activamente de su puesta en escena: incluso, en entrevistas que se hicieron a los habitantes de algunos barrios periféricos en la ciudad, acerca de la imagen que más inmediatamente retraían cuando pensaban en la Plaza de Bolívar, los actores se referían, más bien, a la catedral, al edificio de la gobernación o a la escultura Adán y Eva (1978), del escultor Guillermo Botero G., pero en ningún momento retraían la imagen del Bolívar Cóndor. Pero respecto al porqué de este distanciamiento o de una "pobre visualización del peatón" en cuanto a la imagen de esta obra, Reyes (2016) menciona:

\section{El Bolívar Cóndor está mal ubicado, pues tiene un pedestal demasiado alto [le aparece otra escul- tura superpuesta, diríamos], que hace que esté completamente alejado de la realidad, está fuera de órbita [...], intocable, [lo que la hace] casi un sacrificio para verla [...] el Bolívar Cóndor no lo vemos, está volando [...] la escultura del Bolívar Cóndor, es una escultura fría [y] no genera nin- gún sentido de pertenencia. (Informante N. ${ }^{\circ}$ 1)}

La obra de arte, en este caso, si bien hace parte del mobiliario urbano de la ciudad, llega también a constituirse en un elemento común, cotidiano o normal, a fin de "restituir al hombre en su carácter de peatón, de ser humano" (Reyes, 2016), su sensibilidad y su carácter de ciudadano, y de potenciar "cambios en la conducta de los seres humanos" (Informante N. ${ }^{\circ} 1$ ), pues el artista "pone su obra para que todos los ciudadanos participen del arte" (Informante N. ${ }^{\circ} 1$ ).
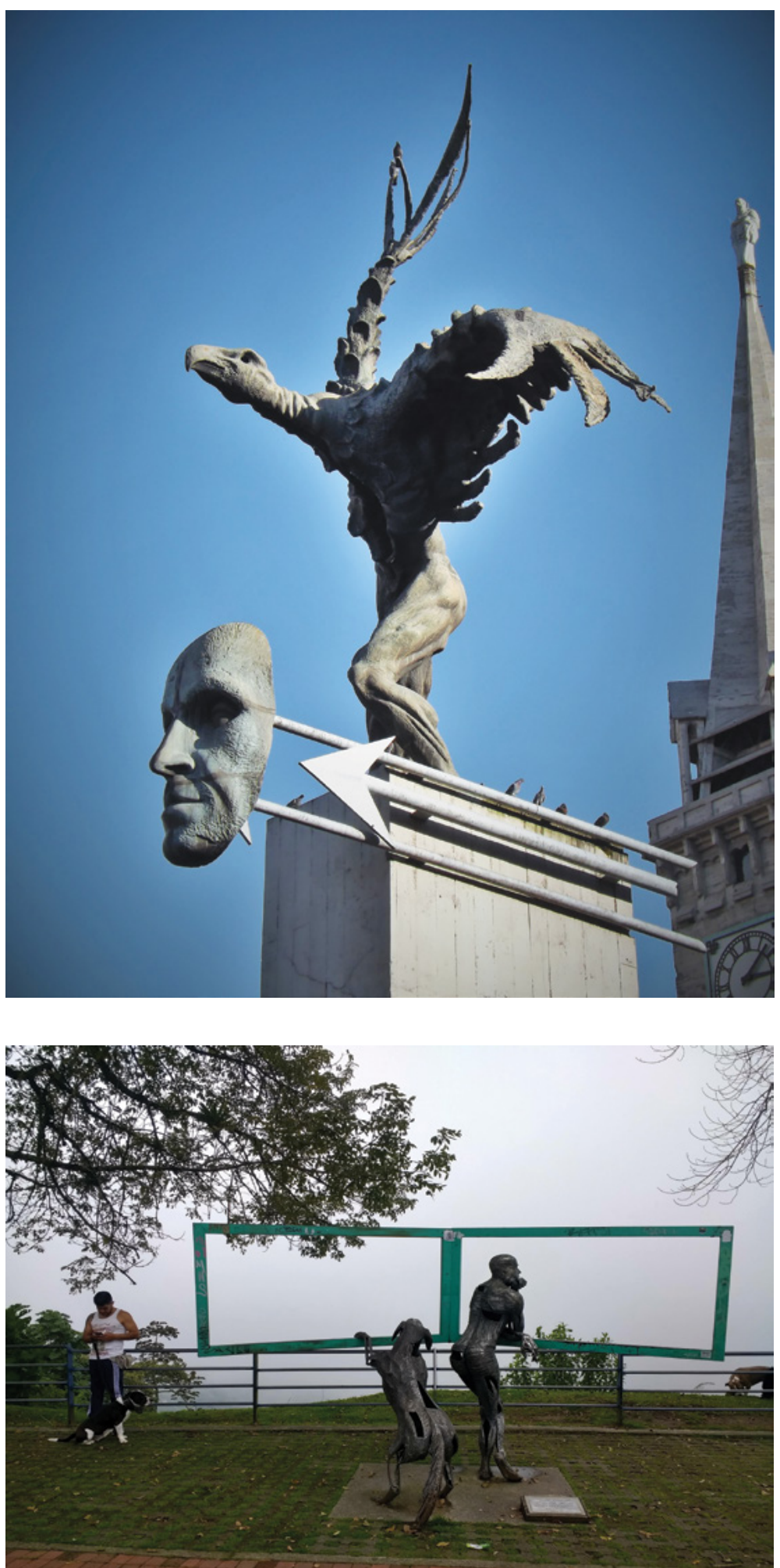

Así, entonces, la obra de arte y el espacio público, en el caso del Bolívar Cóndor y la plaza, no se constituyen en "total armonía visual y espacial", en función de la trama urbana, y que a los actores no les resulte ajena, ni en función de que ella pueda llegar también a transformar el entorno "convirtiéndose en un elemento de buena recordación" (Informante N. ${ }^{\circ} 1$ ).

Contrariamente a esa situación de distanciamiento visual (imagen) y espacial (lugar de encuentro y de atracción o toponímico) que connota el Bolívar Cóndor y la plaza entre los actores, se propone el caso de la obra de arte urbano intitulada Desde Chipre (2000), que aparece en la figura 6, y realizada por el escultor y profesor Alberto Reyes; una escultura en lámina de hierro y soldadura, ubicada en bulevar del barrio Chipre, o Avenida 12 de Octubre: se trata de un hombre y
A Figura 5. El Bolívar Cóndor

Fuente: recuperado de: Young Shanahan, Flickr. http://www.flickr.com/photos/ youngshanahan/38644239714 (2012) CC-BY 2.0

(A) Figura 6. Desde Chipre. A

Fuente: Recuperado de: http://upload.wikimedia.org/ wikipedia/commons/3/32/ Mirador de Chipre\%2C Manizales.jpg , (2018) CС-BY-SA 4.0 
su perro, en pose de observadores a través de una ventana que les permite apreciar el paisaje que se despliega hacia el occidente de la cordillera Central, con su atardecer, los colores y las casas.

De acuerdo con el autor de la obra, esta fue posible, pues

\section{[...] caminando por Chipre (el barrio), y mirando un atardecer, esos colores, esas casitas, ese pai- saje [...] hermoso [me dije], ya se quien se puede quedar aquí [de manera permanente], [...] el ser humano, representado en un hombre, acompa- ñado de alguien que sea fiel [...], el perro [...] la compañía de un perro (pues), que más idea de lealtad que la de un perro [...] es el único que se alegra cuando uno llega a la casa, y nos mueve la cola. (Informante N. ${ }^{\circ}$ )}

Para este caso, la obra de arte urbano Desde Chipre, antes que redundar en el espacio públiCo, enriqueció y transformó el lugar, y empleando la terminología de Lynch (1966), se plantea en ese entorno como elemento de imaginabilidad, en tanto el público o los visitantes del lugar la identifican como una "imagen indiscutible", que, si bien no aporta elementos sustanciales para ofrecer referencias de orientación en el ámbito de la ciudad, la obra es también "vívidamente identificable" (Lynch, 1966), pues traduce elementos de buena recordación; incluso, los actores "juegan con la obra", bien para tomarse una foto, para sorprenderse o para participar de la obra misma, como pudo constatarse tanto en el trabajo etnográfico como en el levantamiento de entrevistas, al requerir a los actores acerca de lo que más les llamaba la atención en su visita al bulevar de Chipre:

[...] las obleas y la figura del hombre y su perro; incluso es habitual encontrar en los registros fotográficos familiares, no menos de una fotografía relacionada con el bulevar de Chipre, y, también, claro está, no se sustraen en esos registros una foto del personaje que acompaña la figura del hombre y su perro, constituyendo para esta obra de arte urbano, "Desde Chipre", su "razón de estar allí. (Informante N. ${ }^{\circ}$ 1)

Aquí, entonces, gana la obra artística en cuanto posibilidad de interactuar con el actor, al "conversar con la obra", pero así también el espacio público se vuelve de todos como "consentimiento de la comunidad", integrado a la trama urbana y su desarrollo, en términos de transitabilidad, recorridos, lúdica y paisajes, lo que reivindica la urbanidad como derecho a la ciudad y a su democratización, de cara a un urbanismo agresivo, restrictivo y normatizado (vigilado), cuya única lógica es la rentabilidad espacial y financiera en la ciudad.

\section{Discusión y conclusiones}

La reflexión a propósito de los monumentos, el arte urbano y el espacio público permite mostrar la importancia epistémica, en el contexto de la ciudad contemporánea, de la categoría del construccionismo social, en tanto posibilidad de una comprensión analítica y conceptual en la que los actores participan de esa realidad, la interpretan y llegan incluso a modificarla; esto último solo es aprehensible para el investigador de la trama urbana, a partir de categorías como las representaciones sociales, a fin de aprehender, a través la etnografía y la acción participante, lo que el investigador abstrae, interpreta y codifica, o que, de acuerdo con los sociólogos urbanos, tipifica (tipologías), a manera de conductas, como lenguaje propio de la ciencia social. Así, entonces, puede inferirse que si existe desprendimiento de una concepción compartimentada entre los monumentos, el arte urbano y el espacio público, ello ofrece la perspectiva de un replanteamiento acerca de su importancia en el entorno urbano y del papel que realmente juegan los actores sociales, pero reiterando la necesidad de incorporar una aprehensión holística, lo que ofrecería otra forma de comprender la ciudad contemporánea.

Los monumentos conmemorativos o rememorativos en la ciudad de Manizales suelen expresar una condición de trashumancia o de invisibilidad; incluso, no constituyen, en su mayoría, una "imagen ambiental eficaz" (Lynch, 1966). Empero, el monumento La torre del cable ofrece una posibilidad de interpretación y de representación social, así como de imaginabilidad en la trama urbana de la ciudad; en parte, ello se debe a una nueva centralidad que emerge en la ciudad, al carácter comercial en el que se ubica el monumento y, también, como lugar de encuentro o toponímico; particularmente, entre los jóvenes: los actores o los peatones ubican su importancia y lo refieren aún para orientarse, y también resulta importante en el entorno donde se ubica la estructura, contrario al Monumento a los colonizadores, que, si bien es la expresión simbólica más acabada en la historia de la ciudad, no adquiere para los actores una significación ni una representación más allá de la ocasión o el momento en que se comparte la alegría en la zona rosa o por la celebración anual de la feria en la ciudad. De cara a esos momentos, el monumento asume una condición de trashumancia o de invisibilidad.

En el caso del arte urbano, el poco interés que puede despertar tiene que ver, como pudo constatarse, con el traslape entre el monumento y el arte urbano y, más aún, cuando la obra se instala sustrayéndose a las posibilidades de interacción con los actores, quienes hacen posible no solo el contacto directo con la obra, sino que también propician su contenido plástico; así, entonces, no es que la obra se invisibilice o caiga en la condición de trashumante, pues dicha impresión 
solo es posible en una interpretación que sustrae el espacio público, donde se ahonda aún más la situación crítica del arte urbano, así como la de los monumentos.

En el caso del arte urbano, concurre la paradoja, pues, como posibilidad de acceso de todos los ciudadanos en la experiencia estética; sin embargo, lo cierto es que se presume de ciertos aprestamientos o de capital cultural para participar plenamente en ese goce artístico. Así mismo, la obra artística, por autodefinición, se sustrae de un entorno o un espacio público que le ofrezca las mejores posibilidades en su puesta en escena; por otro lado, la relación entre el monumento histórico y el arte urbano como experiencia en el espacio público tiende a confundirse o traslaparse como sensación artística o conmemorativa. Este es el caso del Bolívar Cóndor, en la ciudad de Manizales, al igual que su lectura como monumento y obra de arte al mismo tiempo; empero, más allá de esa ambivalencia, lo cierto es que la escultura en sí misma no logra establecer una relación armónica con el entorno o el espacio público, y aleja cualquier posibilidad de apreciación rememorativa o de goce artístico (representación social) en los actores o los viandantes. Tampoco ofrece elementos como "imagen ambiental eficaz", y escasa recordación. Muy contrario a ello, nos encontramos ante una obra de arte urbano en Desde Chipre, que nos ofrece la mejor apuesta para interactuar con el entorno - en este caso, el bulevar de Chipre-: los actores o los viandantes del lugar gozan estéticamente de la obra, se identifican con ella y el entorno (identidad); además, reivindican un uso democrático del espacio públi$\mathrm{co}$, en un contexto de lógicas restrictivas y normatizadas contemporáneas en la ciudad.

Por último, ¿qué pasa con el espacio público? Regularmente, se lo aborda con una perspectiva intrínseca; esto es, visto en sí mismo. Más allá de eso, se ha planteado una perspectiva analítica; esto es, al poner a dialogar los monumentos, el arte urbano y el espacio público de manera dialéctica, de tal forma que ello permita explicar su importancia en la capacidad para recuperar su sentido y permita reinventar los nuevos escenarios de apropiación y goce en la ciudad, de cara o discutiendo las lógicas del capital financiero o de valor mercantil que parece determinar las representaciones urbanas contemporáneas.

\section{Referencias}

Alcaldía de Manizales. (2018). Mapa turístico de Manizales [mapa]. http://manizales.gov.co/ RecursosAlcaldia/201811272305111789.pdf

Baudino, L. (2008). Una aproximación al concepto de arte público1. Boletín Gestión Cultural N. ${ }^{\circ}$ 16: Arte público.

http://blogs.fad.unam.mx/asignatura/ingrid sosa/wp-content/uploads/2017/08/LujanBaudino-Una-aproximacion-al-conceptode-arte-publico-boletin-Gestion-cultural.pdf

Borja, J. (2000). Ciudadanía y espacio público. Revista Foro, (40), 67-80.

Borja, J. (2002). Participación ciudadana: Una cuestión política. Revista Foro, (45), 83-96.

Borja, J., Drnda, M., Fiori, M., Iglesias, M., y Muxí, Z. (2003). La ciudad conquistada. Alianza Editorial.

Cruz-Arrillaga, J. (2014). El arte público como espacio educativo: Producción, mediación y recepción en el País Vasco y Navarra. AusArt Journal for Research, 2(1), 145-154. https://www.ehu.eus/ojs/index.php/ausart/ article/view/11487/11678
Fu Tuan, Y. (2007). Topofilia: Un estudio de las percepciones, actitudes y valores sobre el entorno. Melusina.

Instituto de Cultura y Turismo. (2005). Vigía del Patrimonio Cultural: Bienes muebles e inmuebles en el espacio público. Manizales.

Lefebvre, H. (1969). El derecho a la ciudad. Ediciones Península.

Lynch, K. (1966). La imagen de la ciudad. Infinito. Maderuelo, J. (1994). La pérdida del pedestal. Visor, Círculo de Bellas Artes.

Ministerio de Cultura. (2010). Legislación y normas generales para la gestión, protección y salvaguardia de Patrimonio cultural de Colombia, Ley 1185 y su Reglamentación. http://nuevamuseologia.net/wp-content/ uploads/2014/12/Ley11854.pdf

Moscovici, S. (1985). La era de las multitudes. Un tratado histórico de psicología de las masas. Fondo de Cultura Económica.

Saénz, R. S. (2017). Representaciones sociales del espacio público en la construcción de ciudad. El caso del parque Olaya Herrera y la Carrera Octava en la ciudad de Pereira. [Tesis de Maestría, no publicada, U. de Caldas].
Sassen, S. (1999). La ciudad global. Eudeba.

Valencia, LI. A., (2006). Desgranando la historia. En Caldas Cien años. Historia y Cultura. Gobernación de Caldas.

Viviescas, F. (1989). Urbanización y ciudad en Colombia: (una cultura por construir en Colombia). Foro Nacional por Colombia, Fondo Editorial.

Yory, C. M. (2002). Del monumento a la ciudad: El fin de la idea de monumento en el nuevo orden espacio-temporal de la ciudad. CEJA Pontificia Universidad Javeriana.

Zabalbeascoa, A. (22 de junio de 2018) La reconquista del espacio público. El País. http://elpais.com/cultura/2018/06/21/ babelia/1529592273_492221.html 
Vol.

NrO. 2 REVISTA DE ARQUITECTURA

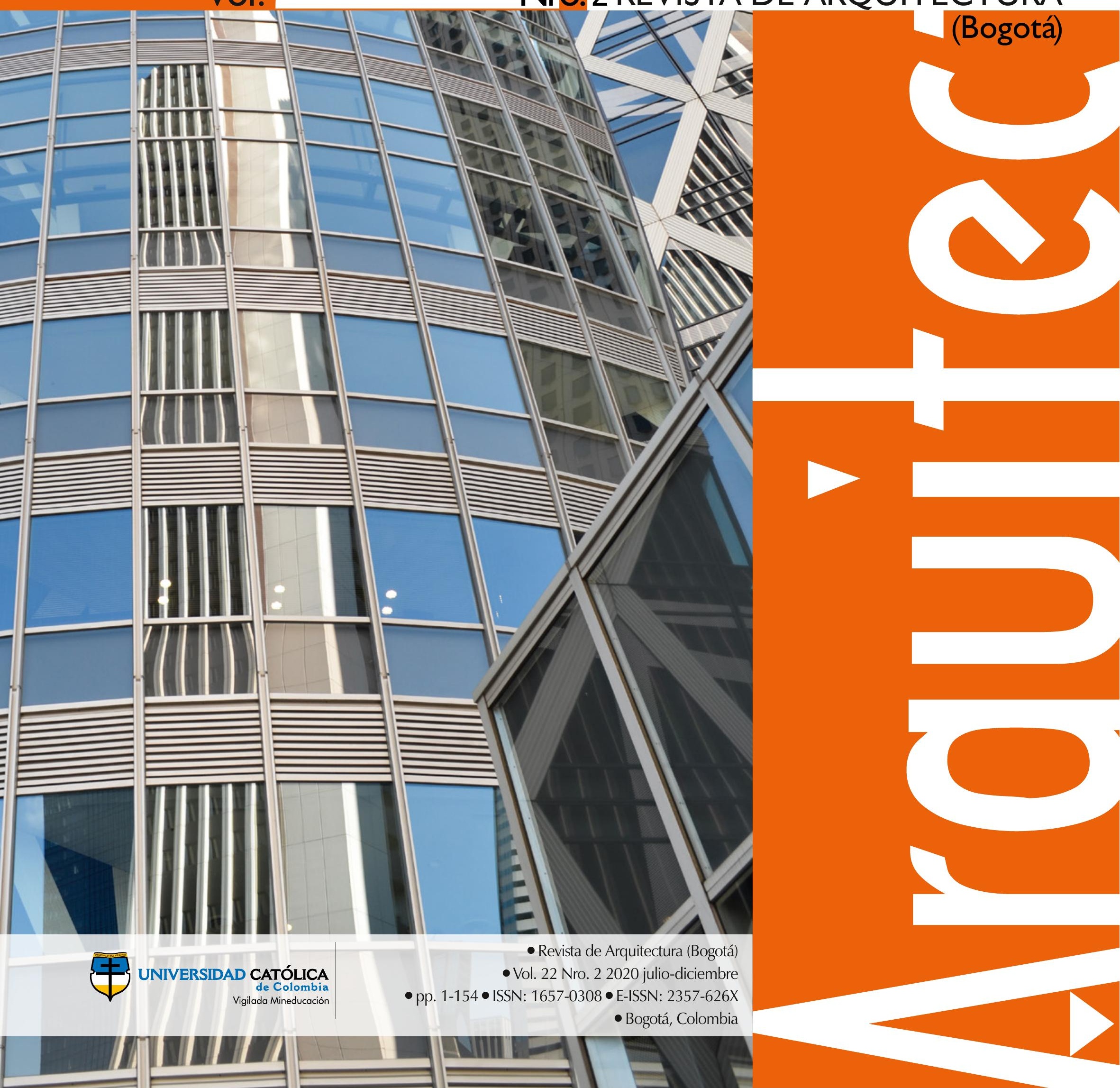


A Portada: Sokkuri (significa reflejo inverso) Mode Gakuen Cocoon Tower, Shinjuku, Tokyo, Japan Fotografía: Arquitecto José Tomás Pachajoa-Herrera (2012, diciembre)

\section{Enfoque y alcance}

La Revista de Arquitectura (Bogotá) ( (ISSN 1657-0308 Impresa y E-ISSN 2357-626X en línea) es una publicación científica seriada de acceso abierto, arbitrada mediante revisión por pares (doble ciego) e indexada, en donde se publican resultados de investigación originales e inéditos.

Está dirigida a la comunidad académica y profesional de las áreas afines a la disciplina. Es editada por la Facultad de Diseño y el Centro de Investigaciones (CIFAR) de la Universidad Católica de Colombia en Bogotá (Colombia).

La principal área científica a la que se adscribe la Revista de Arquitectura (Bogotá) según la OCDE es:

Gran área: 6. Humanidades

Área: 6.D. Arte

Disciplina: 6D07. Arquitectura y Urbanismo

También se publican artículos de las disciplinas como 2A02, Ingeniería arquitectónica; 5G03, Estudios urbanos (planificación y desarrollo); 6D07, Diseño.

Los objetivos de la Revista de Arquitectura (Bogotá) son:

- Promover la divulgación y difusión del conocimiento generado a nivel local, nacional e internacional

- Conformar un espacio para la construcción de comunidades académicas y la discusión en torno a las secciones definidas.

- Fomentar la diversidad institucional y geográfica de los autores que participan en la publicación.

- Potenciar la discusión de experiencias e intercambios científicos entre investigadores y profesionales.

- Contribuir a la visión integral de la arquitectura, por medio de la concurrencia y articulación de las secciones mediante la publicación de artículos de calidad.

- Publicar artículos originales e inéditos que han pasado por revisión de pares, para asegurar que se cumplen las normas éticas, de calidad, validez científica, editorial e investigativa.

- Fomentar la divulgación de las investigaciones y actividades desarrolladas en la Universidad Católica de Colombia
Palabras clave de la Revista de Arquitectura (Bogotá): arquitectura, diseño, educación arquitectónica, proyecto y construcción, urbanismo.

Idiomas de publicación: español, inglés, portugués y francés.

Título abreviado: Rev. Arquit.

Titulo corto: RevArq

\section{Políticas de sección}

La revista se estructura en tres secciones correspondientes a las líneas de investigación activas y aprobadas por la institución, y dos complementarias, que presentan dinámicas propias de la Facultad de Diseño y las publicaciones relacionadas con la disciplina.

Cultura y espacio urbano. En esta sección se publican los artículos que se refieren a fenómenos sociales en relación con el espacio urbano, atendiendo aspectos de la historia, el patrimonio cultural y físico, y la estructura formal de las ciudades y el territorio.

Proyecto arquitectónico y urbano. En esta sección se presentan artículos sobre el concepto de proyecto, entendido como elemento que define y orienta las condiciones proyectuales que devienen en los hechos arquitectónicos o urbanos, y la forma como estos se convierten en un proceso de investigación y nuevo de conocimiento. También se presentan proyectos que sean resultados de investigación, los cuales se validan por medio de la ejecución y transformación en obra construida del proceso investigativo. También se contempla la publicación de investigaciones relacionadas con la pedagogía y didáctica de la arquitectura, el urbanismo y el diseño.

Tecnología, medioambiente y sostenibilidad. En esta sección se presentan artículos acerca de sistemas estructurales, materiales y procesos constructivos, medioambiente y gestión, relacionados con los entornos social-cultural, ecológico y económico.

Desde la Facultad. En esta sección se publican artículos generados en la Facultad de Diseño, relacionados con las actividades de docencia, extensión, formación en investigación o internacionalización, las cuales son reflejo de la dinámica y de las actividades realizadas por docentes, estudiantes y egresados; esta sección no puede superar el $20 \%$ del contenido.

Textos. En esta sección se publican reseñas, traducciones y memorias de eventos relacionados con las publicaciones en Arquitectura y Urbanismo.
A Frecuencia de publicación

Desde 1999 y hasta el 2015, la Revista de Arquitectura (Bogotá) publicó un volumen al año, a partir del 2016 se publicarán dos números por año en periodo anticipado, enero-junio y julio-diciembre, pero también maneja la publicación anticipada en línea de los artículos aceptados (versión Post-print del autor).

La Revista de Arquitectura (Bogotá) se divulga mediante versiones digitales (PDF, HTML, EPUB, XML) e impresascon un tiraje de 700 ejemplares, los tiempos de producción de estas versiones dependerán de los cronogramas establecidos por la editorial.

Los tiempos de recepción-revisión-aceptación pueden tardar entre seis y doce meses dependiendo del flujo editorial de cada sección y del proceso de revisión y edición adelantado.

Con el usuario y contraseña asignados, los autores pueden ingresar a la plataforma de gestión editorial y verificar el estado de revisión, edición o publicación del artículo.
A Canje

La Revista de Arquitectura (Bogotá) está interesada en establecer canje con publicaciones académicas, profesionales o científicas del área de Arquitectura y Urbanismo, como medio de reconocimiento y discusión de la producción científica en el campo de acción de la publicación.

\section{Mecanismo}

Para establecer canje por favor descargar, diligenciar y enviar el formato: RevArq FP20 Canjes

Universidad Católica de Colombia (2020,
julio-diciembre). Revista de
Arquitectura (Bogotá), 22(2),
I-I52. Doi: 10.14718

ISSN: 1657-0308
E-ISSN: 2357-626X
Especificaciones:
Formato: 34 x $24 \mathrm{~cm}$
Papel: Mate II5 g
Tintas: Negro y policromía

Contacto

Dirección postal:

Avenida Caracas No. 46-72.

Universidad Católica de Colombia

Bogotá D.C.(Colombia)

Código postal: 111311

Facultad de Diseño

Centro de Investigaciones (CIFAR).

Sede El Claustro. Bloque "L", 4 piso

Diag. 46A No. $15 b-10$

Editor, Arq. César Eligio-Triana

Teléfonos:

+57 (1) $3277300-3277333$

Ext $3109 \cdot 311205146$

Fax: + 57 (1) 2858895
Correo electrónico:

revistadearquitectura@ucatolica.edu.co cifar@ucatolica.edu.co

Página WEB:

www.ucatolica.edu.co vínculo Revistas científicas

http://publicaciones.ucatolica.edu.co revistas-cientificas http://editorial.ucatolica.edu.co/ojsucatolica/revistas_ucatolica/index.php/RevArq 


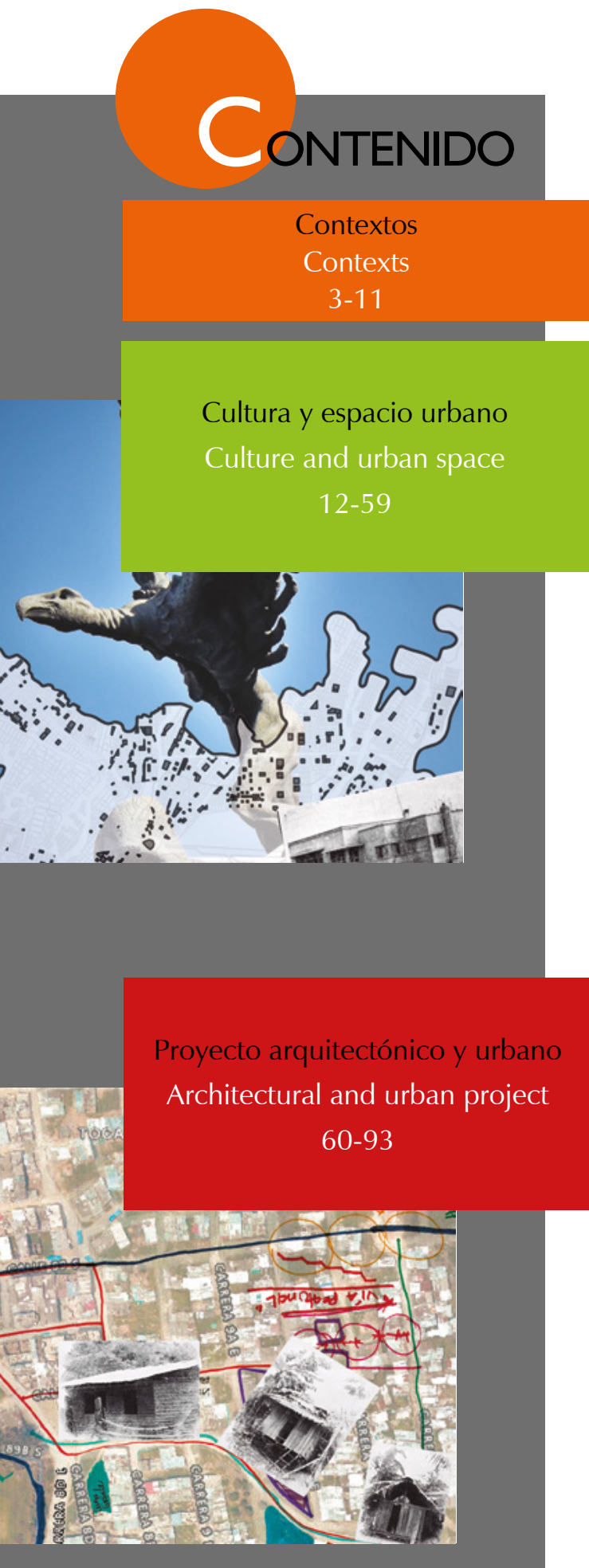

Tecnología, medioambiente y sostenibilidad

Technology, environment and sustainability 94-152

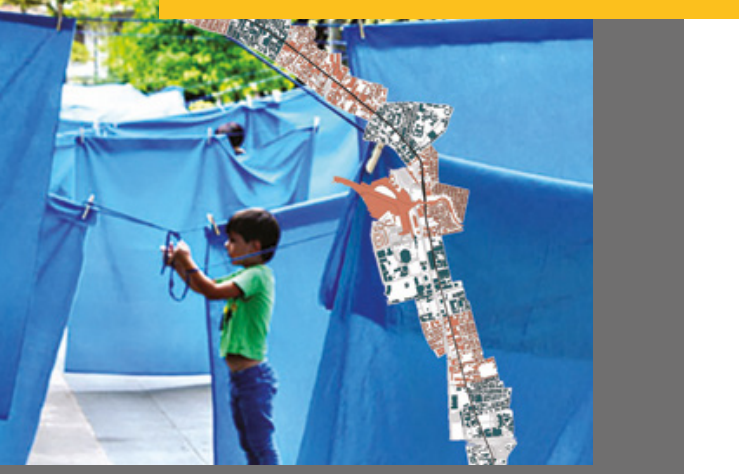

Espacio y tiempo del taller de proyectos arquitectónicos:

la Escuela de Arquitectura de Valencia

Débora Domingo-Calabuig

Laura Lizondo-Sevilla

La comunidad local en la valoración del patrimonio rural.

La escuela Francisco Arias en Lavalle

Isabel Durá-Gúrpide

Matías J. Esteves

ES Hábitat Accesible. Desarrollo de modelos conceptuales urbano-habitacionales.

Alina Delgado-Bohórquez

ES Monumentos y arte urbano: percepciones, actitudes y valores en la ciudad de Manizales.

Rodrigo Santofimio-Ortiz

Sandra Milena Pérez-Agudelo

ES Nueva centralidad en interfase urbano-rural (I-UR)

Caso: sector Umapalca, zona sur de Arequipa Metropolitana

David Jesús Lovon-Caso

Ana de los Ángeles Larota-Sanz

ES Arquitecturas tradicionales y populares: un reto para la historiografía de la arquitectura en Colombia

Guillermo Gutiérrez-Morales

Mito o realidad.

Gustave Eiffel y el templo San Marcos de Arica

Darci Gutiérrez-Pinto

ES La caminabilidad como estrategia proyectual para

las redes peatonales del borde urbano.

Barrio Sierra Morena, Usme.

Marielena Medina-Ruiz

Siudades costeras e indicadores de sostenibilidad:

una aproximación desde el metabolismo urbano de la calle

El caso de la avenida Juan Ponce de León, en San Juan, Puerto Rico

María Helena Luengo-Duque

Fabricación de ladrillos con polvo-residuo de mármol en México. 106

Propiedades físicas y mecánicas del polvo-residuo de mármol

de la provincia de la Comarca Lagunera, en México

C. Ponce-Palafox
Julián Carrillo
A. López-Montelongo

Determinación de emisiones de Gases de Efecto Invernadero (GEI) en una matriz energética sustentable mediante análisis de escenarios.

Estudio de caso en zonas áridas con alto riesgo hídrico

Alba Inés Ramos Sanz

ES La participación infantil en proyectos urbanos.

El juego en espacios públicos para la promoción del aprendizaje

de conceptos ambientales

Carolina Polo-Garzón

Adriana Patricia López-Valencia

Alba Inés Ramos Sanz

ES Gestión territorial y sus implicaciones con el ODS11

Reflexiones desde Colombia y Costa Rica

Tania Giraldo-Ospina

Félix Zumbado-Morales 
Espacio y tiempo del taller de proyectos arquitectónicos:

la Escuela de Arquitectura de Valencia

ن Space and time of the design studio: the Architectu

La comunidad local en la valoración del patrimonio rural. La  escuela Francisco Arias en Lavalle

ن The local community in the appreciation of rural heritage. Francisco Arias ¿ school in Lavalle

Hábitat accesible. Desarrollo de modelos conceptuales

ij Affordable Habitat - The Development of Housing and Neighbourhood

Simulation Models

Monumentos y arte urbano: percepciones, actitudes y valores en la ciudad de Manizales

m ن Manizales $\stackrel{\infty}{+}$ Umapalca, zona sur de Arequipa Metropolitana

New Centrality in Rural Urban Interface. Case: Sector Umapalca, South Zone of Metropolitan Arequip

0

Arquitecturas tradicionales y populares: un reto para la

historiografía de la arquitectura en Colombia

ن Traditional and popular architectures: a challenge for architecture

这

¿ேं

\section{Ciudades costeras e indicadores de sostenibilidad:}

よ

caso de la avenida Juan Ponce de León, en San Juan, Puerto Rico

Coastal cities and sustainability indicators: an approach from the urban

metabolism of the street. The case of Juan Ponce de León avenue, in San Juan, Puerto Rico

Fabricación de ladrillos con polvo-residuo de mármol en México. - Propiedades físicas y mecánicas del polvo-residuo de mármol de 으 la provincia de la Comarca Lagunera, en México

ن Physical and mechanical properties of bricks with dust residue from marble in

México.Physical and mechanical properties of the marble dust-residue from the Comarca Lagunera Province, in Mexico

\section{Julián Carrillo}

Determinación de emisiones de Gases de Efecto Invernadero * (GEI) en una matriz energética sustentable mediante análisis de

- escenarios. Estudio de caso en zonas áridas con alto riesgo hídrico ن Determination of greenhouse gas emissions (GHG) in a sustainable energy matrix $\varangle \quad$ through scenario analysis. Case Study in arid zones with high hydric risk

\section{La participación infantil en proyectos urbanos. El juego en}

ㄴ espacios púb

$\stackrel{2}{\sim}$ ambientales

ن Children's participation in urban projects. Play in public spaces for the

$\varangle$ promotion of the learning of environmental concepts Gestión territorial y sus implicac
desde Colombia y Costa Rica

₹ desde Colombia y Costa Rica

Land Management and its implications with SDG II Reflections from

ن Colombia and Costa Rica

¿ Tania Giraldo-Ospina
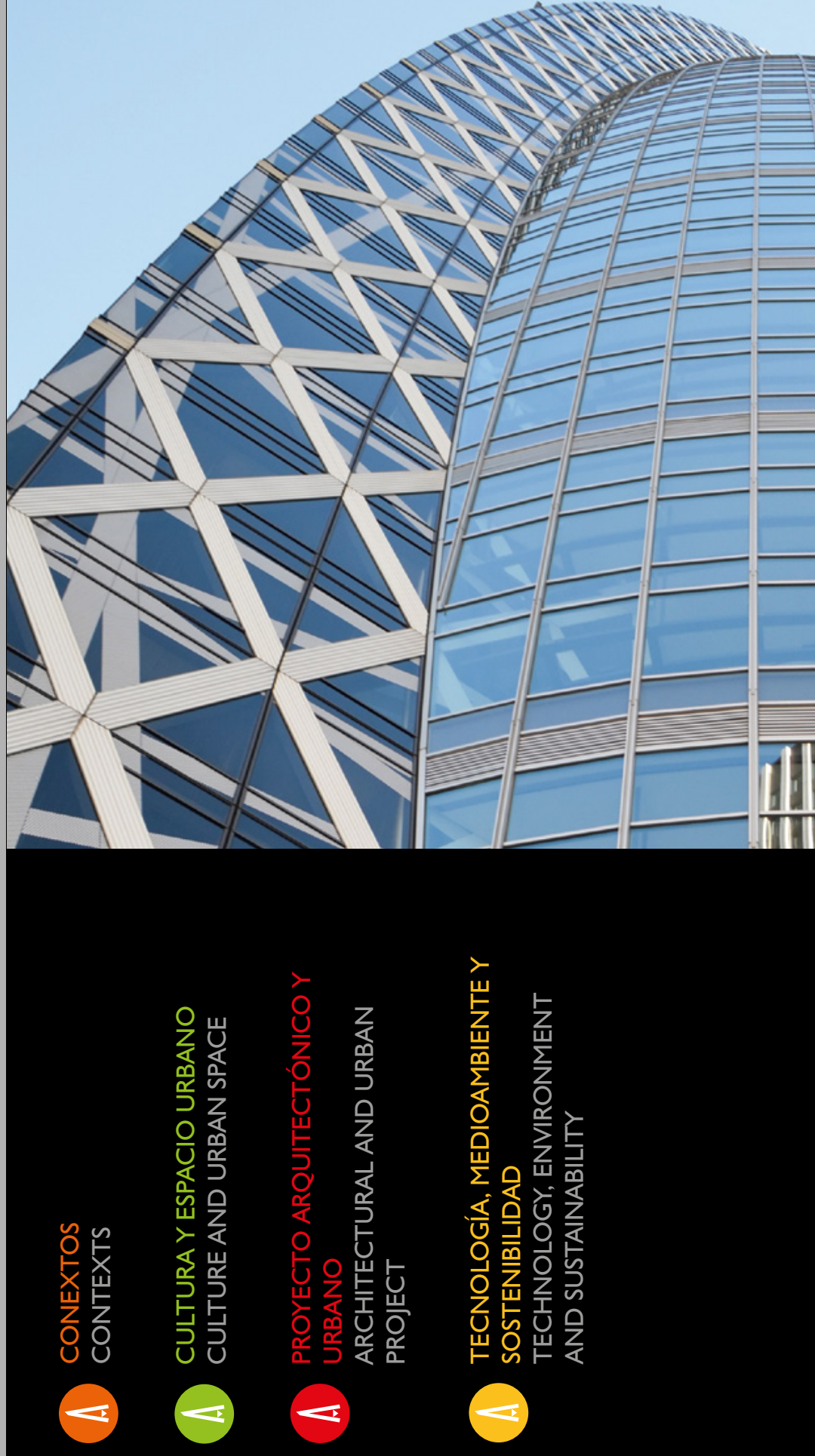

La Revista de Arquitectura es de acceso abierto, arbitrada e indexada y está presente en:

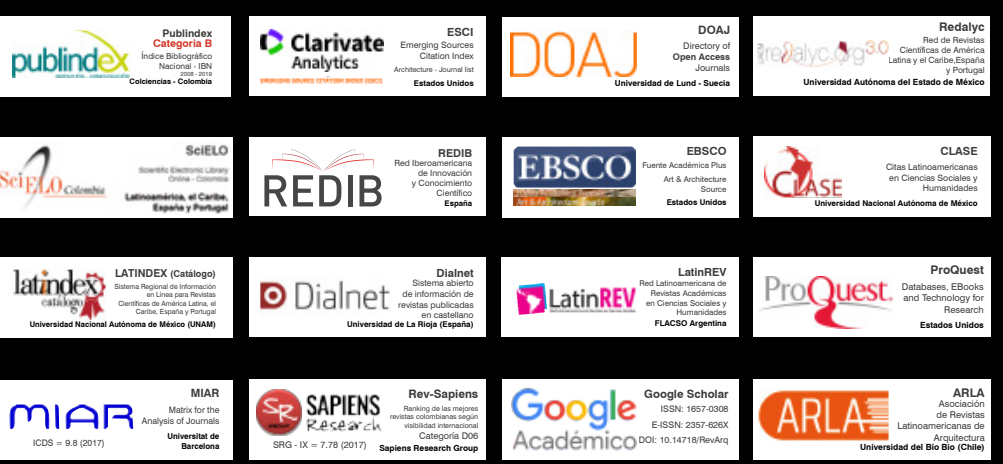

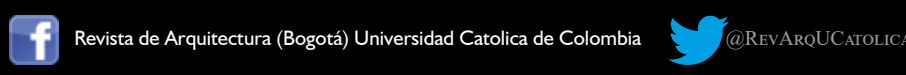

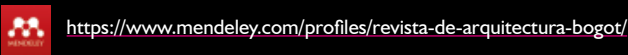

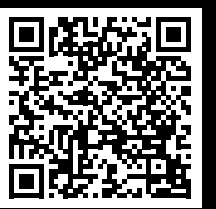

† UNIVERSIDAD CATÓLICA

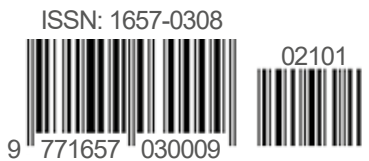

